\title{
Comparison between Wound Healing in Induced Diabetic and Nondiabetic Rats after Low-Level Laser Therapy
}

\author{
SYLVIA BICALHO RABELO, D.D.S., M.S.D., ${ }^{1}$ ANTONIO BALBIN VILLAVERDE, Ph.D., ${ }^{1}$ \\ RENATA AMADEI NICOLAU, D.D.S., Ph.D., ${ }^{1}$ MIGUEL A. CASTILLO SALGADO, Ph.D., ${ }^{2}$ \\ MILENE DA SILVA MELO, M.S.D., ${ }^{1}$ and MARCOS TADEU T. PACHECO, Ph.D. ${ }^{1}$
}

\begin{abstract}
Objective: The aim of this work was to compare the effect of low-level laser therapy (LLLT) on the wound healing process in nondiabetic and diabetic rats. Background Data: Among the clinical symptoms caused by diabetes mellitus, a delay in wound healing is a potential risk for patients. It is suggested that LLLT can improve wound healing. Methods: The tissue used for this study was extracted from animals suffering from diabetes, which was induced by Streptozotocin ${ }^{\circledR}$, and from nondiabetic rats. Animals were assembled into two groups of 25 rats each (treated and control) and further subdivided into two groups: diabetic $(n=15)$ and nondiabetic $(n=10)$. A full-thickness skin wound was made on the dorsum area, with a round 8-mm holepunch. The treated group was irradiated by a HeNe laser at $632.8 \mathrm{~nm}$, with the following parameters: $15 \mathrm{~mW}$, exposition time of $17 \mathrm{sec}, 0.025 \mathrm{~cm}^{2}$ irradiated area, and energy density of $10 \mathrm{~J} / \mathrm{cm}^{2}$. Square full-thickness skin samples (18 $\mathrm{mm}$ each side, including both injured and noninjured tissues) were obtained at 4, 7, and 15 days after surgery and analyzed by qualitative and quantitative histological methods. Results: Quantitative histopathological analysis confirmed the results of the qualitative analysis through histological microscope slides. When comparing tissue components (inflammatory cells, vessels and fibroblast/area), we found that treated animals had a less intense inflammatory process than controls. Conclusion: Results obtained by both qualitative and quantitative analyses suggested that irradiation of rats with $\mathrm{HeNe}(632.8 \mathrm{~nm})$, at the tested dose, promoted efficient wound healing in both nondiabetic and diabetic rats as, compared to the control group.
\end{abstract}

\section{INTRODUCTION}

D IABETES MELLITUS is a chronic organic disorder that affects many people and procedures uncomfortable clinical symptoms. Complications include impaired wound healing, circulatory alterations, decreased collagen production, and skin defects. ${ }^{1-5}$ It has been suggested that diabetes mellitus causes macro- and microvascular alterations, as well as neurological diseases. Some authors have demonstrated that lowlevel laser therapy (LLLT) stimulates wound healing, by increasing collagen deposition and blood flow in the wound area. ${ }^{6-13}$ Some lasers, when used with the proper parameters, affect fibroblasts and collagen production in vitro, and promis- ing results have been found utilizing the HeNe laser (632.8 $\mathrm{nm}$ ) with multiple exposures. ${ }^{9,14-19}$

One effect of laser therapy $\left(5 \mathrm{~J} / \mathrm{cm}^{2}\right)$ is increased local blood flow in normal human skin of the sole of the foot. ${ }^{6}$ A comparative study of LLLT on fibroblasts in vitro, using fluence of 2 $\mathrm{J} / \mathrm{cm}^{2}$ and various irradiances, concluded that the proliferation rate of human gingival fibroblasts was increased when under conditions of nutritional deficit and stress. ${ }^{14}$

Laser parameters (such as wavelength, time of exposure, and dosage) used for in vivo studies of the effect of LLLT on wound healing have not been standardized yet. ${ }^{11,20}$ It is difficult to compare results from different experiments when laser parameters are variable.

${ }^{1}$ Instituto de Pesquisa e Desenvolvimento (IP\&D), Universidade do Vale do Paraiba (UNIVAP), São José dos Campos, São Paulo, Brazil.

${ }^{2}$ Faculdade de Odontologia (FOSJC), Universidade Estadual Paulista (UNESP), São José dos Campos, São Paulo, Brazil. 
However, it is known that LLLT (fluence of $2 \mathrm{~J} / \mathrm{cm}^{2}$ ) affects fibroblast proliferation in vitro and that the condition of cell stress intensifies laser's biological effect. Additionally, LLLT has beneficial effects on human chronic wound closure by stimulating angiogenesis and scarring at the damaged area. ${ }^{14,16}$

One in vivo experiment showed that the HeNe laser stimulated collagen synthesis during wound healing in rats. The most effective fluence was $4 \mathrm{~J} / \mathrm{cm}^{2}$, and the rate of wound closure was enhanced days 3-12 after surgery. ${ }^{21}$

Among the different lasers used for LLLT, the HeNe and others with nearby wavelengths were found to be the most effective for wound healing. ${ }^{21-25}$

The aim of this study is to investigate the biostimulatory effect of HeNe laser irradiation, at $632.8 \mathrm{~nm}$ and $10 \mathrm{~J} / \mathrm{cm}^{2}$ of fluence, on wound healing in rats suffering from diabetes induced by Streptozotocin ${ }^{\circledR}$, as compared to nondiabetic rats. A quantitative analysis was accomplished to confirm qualitative histological observations of samples containing wound healing tissues.

\section{METHODS}

\section{Animals}

Fifty male Wistar rats (Rattus norvergicus albinus), weighing 180-200 g, were used for this study. Animals were observed for an adaptation period of 7 days. Then, they were separated into two groups of 25 animals each, hereafter known as treated and control groups, respectively. Each of those groups was then subdivided into two groups: diabetic (15 animals) and nondiabetic (10 animals). Animals were housed in standard plastic cages, and when urine collection was necessary, they were individually caged in metallic metabolic cages. The animals were kept under constant conditions of temperature $\left(20 \pm 1^{\circ} \mathrm{C}\right)$ and natural light, with ad libitum access to food and water. All animals were physically alike, and the diabetes condition was induced by an intravenous injection of Streptozotocin ${ }^{\circledR}$.

\section{Ethical aspects}

The animals were handled in accordance with national guidelines for the humane treatment of laboratory animals. This study was approved by the Committee of Ethics in Research at the Universidade do Vale do Paraíba (UNIVAP), Brazil, under protocol number A005/2002/CEP.

\section{Diabetes induction and glucose control}

Diabetes was induced for 30 animals, after they were anesthetized with an intramuscular injection of Zoletil ${ }^{\circledR} 50$ Virbac $0.1 \mathrm{cc} / 100 \mathrm{~g}$ body weight. The control group received a buffer intravenous injection to simulate the diabetes induction. A solution of Streptozotocin ${ }^{\circledR}$ in $0.05 \mathrm{M}$ citrate buffer, $\mathrm{pH} 4.2$, was injected through the caudal vein, at a dosage of $65 \mathrm{mg} / \mathrm{kg}$ of body weight.

To establish a baseline, all animals had their blood glucose levels measured. The nondiabetic condition was confirmed by an initial value of glucose of $<200 \mathrm{mg} / \mathrm{dL}$ of blood. The diabetic condition was set at a glucose level of $>217 \mathrm{mg} / \mathrm{dL}$ of blood. The blood examination, utilizing a glucometer Prestige ${ }^{\circledR}$ LX, was done at the $7^{\text {th }}$ day post-induction and, after that, once a week throughout the entire experiment. Glucose levels in the urine were also measured to confirm a stable diabetes condition, around the $15^{\text {th }}$ day after induction.

\section{Urinary analysis}

Diabetes was confirmed through urinary analysis of the glucose level. Urine samples were collected during $24 \mathrm{~h}$, with animals individually housed in metallic metabolic cages, between the $15^{\text {th }}$ and $17^{\text {th }}$ days after diabetes induction. Nondiabetic animals also had urine samples analyzed.

\section{Wounding procedure}

After diabetes was confirmed and with the high blood glucose levels stabilized for more than 15 days after induction, a small dorsal surgery was performed with animals under anesthesia by intramuscular injection of Zoletil ${ }^{\circledR} 50$ Virbac 0.1 $\mathrm{cc} / 100 \mathrm{~g}$ body weight. The dorsal area was shaved, and a fullthickness skin wound was aseptically made on the right side, with a round 8.0-mm hole-punch. Wounds were kept open throughout the entire experiment, without dressing.

After the wounding procedure was finished, animals were housed again and observed until the study was finished.

\section{Experimental groups}

Both laser irradiated and control groups were treated exactly the same way until the end of the surgical procedure. Following this procedure, the 25 animals from the treated group (diabetics and nondiabetics) were exposed to laser irradiation three times a week, whereas the control group was only observed. Full-thickness square skin samples with $18-\mathrm{mm}$ sides (including both injured and noninjured tissues) were obtained at 4, 7, and 15 days of healing after surgery. Samples were fixed in $10 \%$ buffered formaldehyde, and for histopathologic analysis, they were paraffin embedded, sectioned $6 \mu \mathrm{m}$ thick, and stained with hematoxylin and eosin.

\section{Laser irradiation}

A continuous wave (CW) HeNe laser (Spectra-Physics ${ }^{\circledR}$, model 127), at the wavelength of $632.8 \mathrm{~nm}$ and with an output power of $15 \mathrm{~mW}$, was used to irradiate the animals' wounds. Before starting the experiment, the laser was calibrated using a 2-W Broadband Power/Energy Meter (model 13 PEM 001/J). The laser fluence on the rat skin was $10 \mathrm{~J} / \mathrm{cm}^{2}$, corresponding to an irradiated area of $0.025 \mathrm{~cm}^{2}$ and an exposure time of 17 sec. Wounds were irradiated at only one point, at their central region.

\section{Qualitative histopathological analysis}

Histopathological analysis was performed by observing the superficial area of wound tissue and the dermis underneath. Study the evolution of wound healing, we analyzed the degree of re-epithelialization (number of cell lines), granulation tissue formation, inflammatory cellular migration, fibroblast proliferation, collagen deposition, and neovascularization. 


\section{Quantitative histological analysis}

A quantitative histopathological analysis was performed to confirm the quality of the tissue observed in the histological microscope slides. That analysis was accomplished with a camera-coupled microscope and a computer, using the software Leica Qwin $\mathrm{RGB}^{\circledR}$. Each microscope slide, containing a wound area defective tissue, was observed at $400 \times$ magnification. Superficial and depth dermis were analyzed. Vessels, inflammatory cells, and fibroblasts were quantified by only one observer. The automatic counting system was discarded to avoid identifying errors. Each sample was analyzed three times, considering an observation area of $5 \times 10^{-2} \mathrm{~mm}^{2}$, based on pixels of $4 \times 10^{-4} \mathrm{~mm}$.

\section{Statistical analysis}

We used Prism ${ }^{\mathrm{TM}} 2.0$ software to carry out the statistical analysis. The one-way analysis of variance (ANOVA), complemented by the Bonferroni test, was performed to verify if significant differences $(p<0.05)$ were observed between the mean values of the number of cells and vessels presented by the treated and the control groups, for diabetic and nondiabetic animals.

\section{RESULTS}

The concentration of glucose, expressed by $\mathrm{mg} / \mathrm{dL}$ of blood, was monitored for all animals during the experiment. The initial glucose mean values, before diabetes induction, were approximately $110 \mathrm{mg} / \mathrm{dL}$. From the $7^{\text {th }}$ day after diabetes induction, the blood glucose level remained almost stable. Stability was established from the 15th day after diabetes induction.

The diabetic condition was confirmed when glucose was also present in the urine samples. A mean value of $578 \mathrm{mg} / \mathrm{dL}$ for glucose in urine was found in the animals from both diabetic groups, treated and control.

The wound healing process was monitored throughout the experiment, by macroscopic and microscopic analyses.

\section{Macroscopic evolution}

From a macroscopic analysis of the superficial wound area, we found that treated animals (diabetic and nondiabetic) showed accelerated reduction of the wound area when compared to controls. Area reduction was significant at the $7^{\text {th }}$ day $(p<0.04)$, when the group that received LLLT presented better healing and reduced wound size compared to controls. Only small differences were found at the beginning of the healing process ( $4^{\text {th }}$ day) and at the second week (15 days after surgery). The diabetic group presented a slower healing process than the nondiabetic group.

\section{Microscopic qualitative analysis}

Qualitative histopathological analysis was used to evaluate the healing process of the wound area and surrounding tissues. Samples were extracted at $4^{\text {th }}, 7^{\text {th }}$, and $15^{\text {th }}$ days of the healing process, for all treated and control groups.

Treated animals had a less intense inflammatory process than controls, for animals that belong to the same group, dia- betic or not. Diabetic animals showed more intense inflammatory response when compared to nondiabetic animals. At the three healing times, we observed the following:

i. 4 days-Samples from the treated group showed granulation tissue with few vessels and infiltrated mononuclear inflammatory cells forming groups. Samples from the control group presented extensive capillarity and mononuclear inflammatory cells distributed over the entire wound area. The microscope slides from diabetic animals presented congested granulation tissue, with intense inflammatory cell density, poor organization, and congested capillaries when compared to the nondiabetic group.

ii. 7 days - The treated group showed granulation tissue with fewer capillaries and a better quality of epithelialization than the control group, for both diabetic and nondiabetic animals. The samples from nondiabetic animals showed smaller inflammatory cell density when compared to diabetic animals; the laser-treated nondiabetic group presented well-organized healing tissue in the best condition.

iii. 15 days-Only small differences were found between diabetic and nondiabetic animals. After 15 days, irradiated groups showed intense fibroblast proliferation and extensive collagen fiber deposition. Epithelialization for the treated group was extensive, and epithelial tissue for the treated group had a better quality of differentiation compared to the control group.

\section{Microscopic quantitative analysis}

Table 1 presents densities of the inflammatory cells, vessels, and fibroblastic cell indices for the control and irradiated groups (nondiabetic and diabetic animals), obtained from an analysis of the superficial and depth dermis. It was possible to verify the following:

i. Inflammatory cells for nondiabetic group-A significant reduction of inflammatory cell density (superficial dermis) occurred during the period between the $4^{\text {th }}(58.3 \pm 2.9)$ and the $7^{\text {th }}(29.5 \pm 3.7)$ days for laser-treated animals $(p=$ $\left.1.25 \mathrm{e}^{-5}\right)$ and also after the second week $(15.1 \pm 1.0, p=$ $0.003)$, whereas the density reduction between the $4^{\text {th }}$ ( 73.4 $\pm 4.4)$ and $7^{\text {th }}(58.9 \pm 5.2)$ days of healing was not significant for the control group. For this group (depth dermis), a significant decrease of inflammatory cells occurred between the $7^{\text {th }}(66.3 \pm 7.8)$ and $15^{\text {th }}(21.1 \pm 2.1)$ days of healing $\left(p=9.64 \mathrm{e}^{-6}\right)$.

ii. Inflammatory cells for diabetic group-Samples from diabetic animals showed a continuous decrease of the inflammatory cell density for control and laser-treated groups throughout the entire experimental period. That decrease was, most of the time, larger for the diabetic group than for the nondiabetic group (control and laser-treated). Figure 1 displays the density of inflammatory cells on the wound surface as a function of the number of days of healing, for the two groups (treated, control), and the subgroups (diabetic and nondiabetic). A comparison between lasertreated and control groups for the same condition (both diabetic or not), and at a certain time of healing, days 4-7 and days $7-15$, indicated a significant decrease $(p<0.05)$ of the inflammatory cell density for laser-treated samples. 
Table 1. Analysis of the Inflammatory Cells, Vessels, and Fibroblastic Cells IndeXes (Area $\left.=5 \times 10^{-2} \mathrm{MM}^{2}\right) \mathrm{OF}_{\mathrm{THE}}$ CONTROL AND IRradiated Groups (NONDiABETIC AND Diabetic ANimals)

\begin{tabular}{|c|c|c|c|c|c|c|c|c|}
\hline \multirow[b]{3}{*}{ Days } & \multicolumn{4}{|c|}{ Nondiabetic group } & \multicolumn{4}{|c|}{ Diabetic group } \\
\hline & \multicolumn{2}{|c|}{ Control } & \multicolumn{2}{|c|}{ Laser } & \multicolumn{2}{|c|}{ Control } & \multicolumn{2}{|c|}{ Laser } \\
\hline & Surface & Depth & Surface & Depth & Surface & Depth & Surface & Depth \\
\hline \multicolumn{9}{|c|}{ Inflammatory cells } \\
\hline 4 & $73.4 \pm 4.4$ & $70.9 \pm 6.9$ & $58.3 \pm 2.9$ & $50.9 \pm 3.3$ & $139 \pm 14 a b c$ & $141 \pm 18 \mathrm{abc}$ & $87.3 \pm 7.6$ & $93.6 \pm 5.4^{\mathrm{d}}$ \\
\hline 7 & $58.9 \pm 5.2$ & $66.3 \pm 7.8$ & $29.5 \pm 3.7$ & $38.5 \pm 3.9$ & $93.6 \pm 7.1^{\mathrm{abc}}$ & $110 \pm 6.0 \mathrm{abc}$ & $60.3 \pm 7.4^{\mathrm{d}}$ & $73.6 \pm 8.4^{\mathrm{d}}$ \\
\hline 15 & $22.0 \pm 1.5$ & $21.1 \pm 2.1$ & $15.1 \pm 1.0$ & $15.9 \pm 0.9$ & $42.7 \pm 7.8^{c}$ & $50.5 \pm 11^{\mathrm{abc}}$ & $30.1 \pm 4.3$ & $26.1 \pm 2.4$ \\
\hline \multicolumn{9}{|l|}{ Vessels } \\
\hline 4 & $78.4 \pm 5.7 \mathrm{e}$ & $73.0 \pm 4.1$ & $64.7 \pm 2.7$ & $67.0 \pm 2.5$ & $66.3 \pm 12$ & $74.3 \pm 4.7$ & $44.0 \pm 4.8$ & $50.6 \pm 8.7$ \\
\hline 7 & $81.2 \pm 2.5^{\mathrm{f}}$ & $94.3 \pm 4.4$ bef & $56.9 \pm 3.0$ & $67.8 \pm 2.4$ & $68.3 \pm 13$ & $64.0 \pm 10$ & $60.6 \pm 7.9$ & $49.8 \pm 6.8$ \\
\hline 15 & $53.4 \pm 6.2$ & $62.9 \pm 4.8$ & $45.5 \pm 4.3$ & $49.6 \pm 3.8$ & $50.3 \pm 6.6$ & $51.5 \pm 8.2$ & $39.8 \pm 9.6$ & $36.6 \pm 6.8$ \\
\hline \multicolumn{9}{|c|}{ Fibroblastic cells } \\
\hline 4 & $145 \pm 5.8$ & $140 \pm 6.7$ & $123 \pm 7.4$ & $125 \pm 7.9$ & $140 \pm 11$ & $157 \pm 11$ & $132 \pm 7.6$ & $137 \pm 6.5$ \\
\hline 7 & $128 \pm 4.7$ & $121 \pm 5.2$ & $106 \pm 6.8$ & $111 \pm 3.9$ & $128 \pm 20$ & $139 \pm 13$ & $128 \pm 18$ & $137 \pm 16$ \\
\hline 15 & $80.2 \pm 4.0$ & $91.7 \pm 4.9$ & $76.8 \pm 3.8$ & $79.0 \pm 4.2$ & $59.0 \pm 4.7$ & $67.8 \pm 9.9$ & $102 \pm 12^{a}$ & $99.8 \pm 11$ \\
\hline
\end{tabular}

Level of statistical significance was calculated for the comparison between the nondiabetic and diabetic groups (control and laser treated). Data are expressed as means \pm SEM.

${ }^{\mathrm{a}-\mathrm{f}} p<0.05$ (a, diabetic control vs. diabetic laser; b, diabetic control vs. nondiabetic control; c, diabetic control vs. nondiabetic laser; d, diabetic laser vs. nondiabetic laser; e, diabetic laser vs. nondiabetic control; f, nondiabetic control vs. nondiabetic laser).

The laser-irradiated diabetic group showed inflammatory cell densities that are similar or even lower than the control group for later healing times. The inflammatory cell density of the diabetic group showed a significant level of difference (diabetic control versus diabetic laser) at the $4^{\text {th }}$ day $(p<0.01)$ and at the $7^{\text {th }}$ day $(p<0.01)$ when laserirradiated animals were compared to control (superficial and depth dermis). A nonsignificant reduction in inflammatory cells was observed for samples from the nondiabetic groups (control and laser-treated).

iii. Vessels and fibroblasts for both groups-Both the nondiabetic and diabetic groups showed a significant decrease in capillarity during only the first week of experiment when control animals were compared to laser irradiated. Quantitative analysis demonstrated a continuous decrease of capillarity in both groups, but the relative number of vessels was lower for the laser-irradiated animals than for the controls for the same period of healing. No significant differences were found for nondiabetic treated, diabetic control, and diabetic treated groups as a function of time of healing. The number of fibroblasts had a significant decrease at the 15 th day for the lasertreated diabetic group compared to the diabetic control group (superficial dermis).

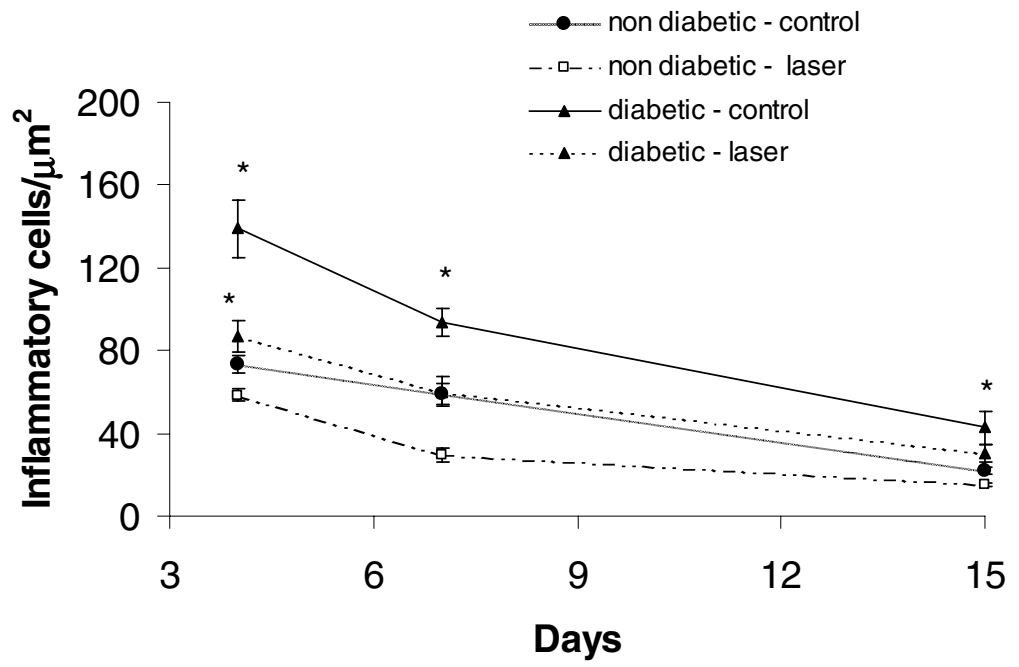

FIG. 1. Inflammatory cells in the wound surface $\left(/ \mu \mathrm{m}^{2}\right)$, versus days after surgery, for all the groups: control and irradiated (laser) nondiabetic and diabetic animals. Symbols represent mean \pm standard error of the mean (SEM). $* p<0.05$ 


\section{DISCUSSION}

Wound healing is a complex biologic and biochemical process that commences right after tissue injury. Low oxygen tension and the formation of platelet plugs characterize the coagulation phase. Macrophages, polymorphnuclear neutrophilis, and lymphocytes appear during the inflammatory phase for debris and infection control, and the secretion of growth factors occurs for fibroplasias, angiogenesis, and reepithelialization.

During the past decade, a growing interest in photomedicine has emerged from the creative use of lasers, giving rise to the field of "laser biostimulation" or "low-level laser therapy" (LLLT). This form of therapy is now widely used for the treatment of a variety of conditions, including wound healing, reduction of edema, and elimination of pain of various etiologies. ${ }^{26}$

In this study, we examined the hypothesis that laser photostimulation can facilitate healing of impaired wounds in experimental diabetes using a rat model. Our results using LLLT show a decreased number of inflammatory cells in the injury site. Previous studies have reported-beneficial effects of LLLT on chronic wound healing, in healthy and nonhealthy rats, as well as in some other small animals. ${ }^{7,10,19-22}$ Since blood flow is increased in the microcirculation during laser therapy, this could explain the enhancement of wound healing and reduced pain. 6,7

Others have suggested that LLLT is beneficial for wound healing in diabetics. They reported that LLLT, at $830 \mathrm{~nm}$, significantly enhanced cutaneous wound tensile strength in a murine diabetic model. ${ }^{13} \mathrm{Yu}$ et al. ${ }^{7}$ showed that LLLT enhanced wound healing in diabetic mice, as evidenced by wound closure and the histopathological evaluation of wounds of treated and untreated animals. Others found ${ }^{21}$ that maximum enhancement of skin wound healing using a HeNe laser was reached at a daily dose of $4 \mathrm{~J} / \mathrm{cm}^{2}$, whereas a slight deceleration was noticed at $20 \mathrm{~J} / \mathrm{cm}^{2}$.

Results from the present experiment seem to indicate that an irradiation of $632.8 \mathrm{~nm}$ at $10 \mathrm{~J} / \mathrm{cm}^{2}$ accelerates wound healing in nondiabetic rats, as well as for induced diabetes. No inhibition effect was found, and treated animals had a better quality of healing tissue. The differences in the reduction of the wound area size were more evident for diabetic animals than for nondiabetic when compared with controls. This fact probably occurred due to stress, caused as a consequence of diabetes. ${ }^{14}$ Only small differences in wound size could be noted between treated and untreated animals at the $4^{\text {th }}$ and $15^{\text {th }}$ days, (i.e., at the beginning and at the end of the experiment). This was because the irradiation time was not enough to produce significant changes at the $4^{\text {th }}$ day, and in the second case (at the $15^{\text {th }}$ day) was due to the fact that healing was almost complete for both groups. On the contrary, significant reductions in wound sizes (at least by a factor of two) were observed for the treated group at the $7^{\text {th }}$ day, when compared to the control, indicating a distinct acceleration of the healing process stimulated by laser irradiation.

Histopathologic evaluation showed better re-epithelialization in treated groups at the $7^{\text {th }}$ and $15^{\text {th }}$ days after surgery than in control animals. Thick epithelium was seen in some cases by the $15^{\text {th }}$ day, with queratin on the surface. Treated animals pre- sented, at the $7^{\text {th }}$ day, a dermis healing tissue with fewer capillaries and more discrete inflammatory cells compared to the untreated group, especially in nondiabetic animals. Fibroblast proliferation in the treated group seemed to be a little more accelerated, with connective tissue showing advanced maturity and organization. Those factors suggest modulation of the inflammatory reaction is the mechanism by which light acts in the healing process.

\section{CONCLUSION}

In conclusion, irradiation of nondiabetic and diabetic rats with $\mathrm{HeNe}$ laser (dose of $10 \mathrm{~J} / \mathrm{cm}^{2}$ at $632.8 \mathrm{~nm}$ ) promoted efficient wound healing for both. The nondiabetic laser-treated groups showed the earliest wound healing when compared to the other groups. Laser-treated groups presented better quality of wound tissues at macroscopic and the microscopic analysis.

\section{ACKNOWLEDGMENTS}

This study was supported by Fundação de Amparo à Pesquisa do Estado de São Paulo (FAPESP).

\section{REFERENCES}

1. Spanheimer, R.G., Umpierrez, G.E., and Stumpf, V. (1988). Decreased collagen production in diabetic rats. Diabetes 37, 371-376.

2. Fortes, Z.B., Garcia Leme, J., and Scivoletto, R. (1984). Vascular reactivity in diabetes mellitus: possible role of insulin on the endothelial cell. Br J Pharmacol. 83, 635-643.

3. Davidson, M.B. (2001). Diabetes Mellitus: Diagnóstico e Tratamento, $4^{\text {th }}$ ed. Rio de Janeiro: Revinter.

4. Goodson, W.H., III, and Hunt, T.K. (1979). Wound healing and the diabetic patient. Surg. Gynecol. Obstet. 149, 600-608.

5. Caballero, A.E., Arora, S., Saouaf, R., et al. (1999). Microvascular and macrovascular reactivity is reduced in subjects at risk for type 2 diabetes. Diabetes 48, 1856-1862.

6. Schaffer, M., Bonel, H., Sroka, R., et al. (2000). Effects of 780-nm diode laser irradiation on blood microcirculation: preliminary findings on time-dependent T1-weighted contrast-enhanced magnetic resonance imaging (MRI). J. Photochem. Photobiol. B. Biol. $54,55-60$

7. Yu, W., Naim, J.O., and Lanzafame, R.J. (1997). Effects of photostimulation on wound healing in diabetic mice. Lasers Surg. Med. 20, 56-63

8. Simunovic, Z., Ivankovich, A.D., and Depolo, A. (2000). Wound healing of animal and human body sport and traffic accident injuries using low-level laser therapy treatment: a randomized clinical study of seventy-four patients with control group. J. Clin. Laser Med. Surg. 18, 67-73.

9. Abergel, R.P., Meeker, C.A., Lam, T.S., et al. (1984). Control of connective tissue metabolism by lasers: recent developments and future prospects. J. Am. Acad. Dermatol. 11, 1142-1150.

10. Lyons, R.F., Abergel, R.P., White, R.A., et al. (1987). Biostimulation of wound healing in vivo by a helium-neon laser. Ann. Plast. Surg. 18, 47-51.

11. Surinchak, J.S., Alago, M.L., Bellamy, R.F., et al. (1983). Effects of low-level energy lasers on the healing of full-thickness skin defects. Lasers Surg. Med. 2, 267-274. 
12. Mester, E., Mester, A.F., and Mester, A. (1985). The biomedcal effects of laser application. Lasers Surg. Med. 5, 31-39.

13. Stadler, I., Lanzafame, R., Evans, R., et al. (2001). 830-nm irradiation increases the wound tensile strength in a diabetic murine model. Lasers Surg. Med. 28, 220-226.

14. Almeida-Lopes, L., Rigau, J., Zângaro, R.A., et al. (2001). Comparison of the low-level laser therapy effects on cultured human gingival fibroblasts proliferation using different irradiance and same fluence. Lasers Surg. Med. 29, 179-184.

15. Young, S., Bolton, P., Dyson, M., et al. (1989). Macrophage responsiveness to light therapy. Lasers Surg. Med. 9, 497-505.

16. Rigau, J. (1996). Acción de la luz láser a baja intensidad en la modulación de la función cellular [Ph.D. dissertation]. Reus, Spain: University of Rovira i Virgil.

17. Stein, A., Benayahu, D., Maltz, M., et al. (2005). Low-level laser irradiation promotes proliferation and differentiation of human osteoblasts in vitro. Photomed. Laser Surg. 23, 161-166.

18. Vinck, E.M., Cagnie, B.J., Cornelissen, M.J., et al. (2005). Green light-emitting diode irradiation enhances fibroblast growth impaired by high glucose level. Photomed. Laser Surg. 23, $167-171$

19. Maiya, G., Kumar, P., and Laxmi, R. (2005). Effect of lowintensity helium-neon (He-Ne) laser irradiation on diabetic wound healing dynamics. Photomed. Laser Surg. 23, 187-190.

20. Conlan, M.J., Rapley, J.W., and Cobb, C.M. (1996). Biostimulation of wound healing by low-energy laser irradiation. J. Clin. Periodontol. 23, 492-496.
21. Kana, J.S., Hutschenreiter, G., Haina, D., et al. (1981). Effect of low-power density laser radiation on healing of open skin wounds in rats. Arch. Surg. 116, 293-296.

22. Al-Watban, F.A.H., and Zhang, X.Y. (1999). The acceleration of wound healing is not attributed to laser skin transmission. Laser Ther. 11, 6-10.

23. Al-Watban, F.A.H., Bernard, L.A., and Zhang, X.Y. (2000). Wound healing efficacy of HeNe laser $(632.8 \mathrm{~nm})$ and pharmacological treatments in normal rats. Lasers Life Sci. 9, 245-254.

24. Tsuchida, T., Aizawa, K., Baba, J., et al. (1991). Wound healing in mice using He-Ne scanning laser. J. Clin. Laser Med. Surg. 9, 265-266.

25. Reddy, G.K., Stehno-Bittel, L., and Enwemeka, C.S. (2001). Laser photostimulation accelerates wound healing in diabetic rats. Wound Rep. Reg. 9, 248-255.

26. At-Watban, F.A.H., and Andres, B.L. (2000). Laser photons and pharmacological treatments in wound healing. Laser Ther. 12, 3-11.

Address reprint requests to: Dr. Antonio Balbin Villaverde IP\&D-Univap

Av Shishima Hifumi 2911

Urbanova, 12244-000

São José dos Campos, SP, Brazil

E-mail: abv@univap.br 